\title{
Knowledge about Epilepsy in University Health Students: A Multicenter Study
}

Priscila de Souza, $\mathrm{MSc}^{1}$; Leslie A. Portes, $\mathrm{MSc}^{2}$; Robert K. Thomas, $\mathrm{PhD}^{3}$; Jorge R. Bonito, $\mathrm{PhD}^{4}$; Marilia Rua, $\mathrm{PhD}^{5}$; Fabio J. Pacheco, $\mathrm{PhD}^{6}$; Phillip Plaatjes, $\mathrm{PhD}^{7}$; Natalia C. Oliveira, $\mathrm{PhD}^{8}$

1- Master in Health Promotion at the Adventist University of São Paulo (Sao Paulo, SP, Brazil), Physical therapist at the Physical Medicine and Rehabilitation Institute, Lucy Montoro Center, University of Sao Paulo (Sao Paulo, SP, Brazil). prifisioterapia@hotmail.com

2- Researcher and professor of the Health Promotion Master Program and undergraduation courses at the Adventist University of São Paulo (Sao Paulo, SP, Brazil). leslie.portes@ucb.org.br

3- Professor and Head of the Department of Science and Exercise at LaSierra University (California, United States of America). rthomas@lasierra.edu

4- Researcher and Professor at Evora University (Evora, Portugal). Member of the Portuguese Society of Education Science. jbonito@uevora.pt.

5- Researcher and Professor of the Health College at Aveiro University (Aveiro, Portugal). Head of the Master Program in Family Health Nursing. mrua@ua.pt

6- Research coordinator at Del Plata Adventist University. (Libertador San Martin, Argentina).cienciaytecnica@uap.edu.ar

7- Professor and Dean of the Faculty of Arts at Helderberg College (Somerset West, South Africa).plaatp@hbc.ac.za.

8- Researcher and professor of the Health Promotion Master Program and undergraduation courses at the Adventist University of São Paulo (Sao Paulo, SP, Brazil).natalia.silva@ucb.org.br

\section{Corresponding Author:}

Natalia Cristina de Oliveira

Estrada de Itapecerica, 5859

Sao Paulo - SP - Brazil

05858-001

Telephone: +551199183 1978

Fax: +5511 21286000

e-mail: natalia.silva@ucb.org.br

Short Title: Knowledge about Epilepsy in University Students 


\begin{abstract}
Epilepsy is a disorder defined as an excessive disorganized electrical discharge in the brain. Even with economic development and improvements in health care around the world, it is estimated that nowadays 50 million people have epilepsy. It is one of the most prevalent neurological diseases, yet it is still surrounded by prejudice, stigma, lack of awareness and wrong attitudes of the population towards the disease. The aim of this study was to evaluate and compare the knowledge about epilepsy in health students from different countries: Brazil, Argentina, Portugal, United States and South Africa. Students were asked to complete a survey regarding knowledge about epilepsy, composed by 55 items related to medical and social aspects of the disease. One hundred and two students participated, $62.2 \%$ of them were female. The total average score was 36.9 (out of a possible score of 55) and Portuguese students had significantly higher values than the American ones $(p=0.025)$. Regarding the medical aspects, on average, students hit $63.8 \%$ of the questions and the students from Portugal had significantly higher average than the ones from the United States $(p=0.0007)$. Statements with lower percent of correct answers were about pathophysiology, medication and treatment of the disease. There were no differences between the scores obtained by the students of each country in the social aspects of the disease, and the percentage of correct answers was $65.2 \%$ on average. Statements with higher percent of mistakes were about sports practice, labor, proceedings in case of convulsion and ability to drive vehicles. General knowledge of senior health students about epilepsy was considered low, however, regarding the medical aspects of the disease, students from Brazil and Portugal exhibited a slightly superior knowledge. Changing the way of seeing and treating people with epilepsy brings as a consequence increased opportunities for these people in different sectors of society. Thus, qualification can contribute to a fairer and more tolerant society in which differences are respected.
\end{abstract}

Keywords: epilepsy; university students; knowledge. 